Available online at GSC Online Press Directory

GSC Biological and Pharmaceutical Sciences

e-ISSN: 2581-3250, CODEN (USA): GBPSC2

Journal homepage: https://www.gsconlinepress.com/journals/gscbps

(RESEARCH ARTICLE)

\title{
Chemo-profiling and assessment of antioxidant activity and antibacterial potentials of selected plants of family Combretaceae
}

\author{
Das Arundhati ${ }^{1,}{ }^{*}$, Samal Kailash Chandra ${ }^{2}$ and Bastia Akshaya Kumar ${ }^{1}$ \\ ${ }^{1}$ Department of Botany, North Orissa University, Sriram Chandra Vihar, Takatpur, Baripada, Mayurbhanj, Odisha. \\ ${ }^{2}$ Department of Agril. Biotechnology, College of Agriculture, OUAT, Bhubaneswar-751003, Odisha.
}

Publication history: Received on 21 January 2020; revised on 30 January 2020; accepted on 01 February 2020

Article DOI: https://doi.org/10.30574/gscbps.2020.10.2.0016

\begin{abstract}
Traditional medicine is used all over the world, especially in developing countries. Though synthetic drugs are very effective but are harmful to human beings because of their side effects. Genus of Terminalia and Combretum species belongs to the family Combretaceae, which contains 20 genera and 600 species as herbs, shrubs, and trees. These plants are used in different traditional medicine for their antioxidant property and also for the treatment of hepatitis and malaria due to the presence of antibacterial properties. The present study is focused on chemo- profiling, screening of the antioxidant compound, antioxidant activities and antimicrobial properties of different Terminalia and Combretum species, namely Terminalia arjuna, T. alata, T. bellerica, T. T. cataappa, T. chebulla, T. bucera and T. mauritiana,, Combretum albidum, C. roxburghii and C. indicum. Four different concentrations (20, 40, 60 and $80 \mathrm{mg} / \mathrm{ml}$ ) of methanolic extracts of leave and bark of these plant species were tested against six bacterial pathogens i.e Streptococcus epidermis, Salmonella enterica, Staphylococcus aureus, Escherichia coli, Bacillus subtillis and Pseudomonas aeruginosa using disc diffusion method. It was observed that the methanolic leaf and bark extract T. arjuna, T. chebulla, and $C$. albidum proved remarkable antibacterial properties against the different bacterial strains. This study will help to know the properties of medicinal plants for making different formulation of different types of green medicine.
\end{abstract}

Keywords: Antibacterial assay; Antioxidant; Chemo-profiling; Combretum species. HPTLC; Terminalia spp.

\section{Introduction}

The family Combretaceae comprises 20 genera with 600 species of which the genus Combretum and Terminalia contain 370 and 200 species, respectively. The genus Combretum is used in folk medicine for the treatment of various diseases such as stomach pain and diarrhoea [1]. Medicinal plants have been used since ancient times in virtually all cultures as a source of medicines [2, 3, 4]. The family Combretaceae is widely distributed in tropical Africa, South America and Asia [5]. Combretum (Loefl.) has been used in the treatment of syphilis, abdominal pains, conjunctivitis, diarrhoea, toothache, and several other diseases. Several plant species of family Combretaceae have antimicrobial activities [6, 7, 8]. Compounds like flavonoids, phenanthrenes, stilbenes, cyclobutanes, and triterpenoids are present in the plants. Nowa-days, oxidative stress or excessive production of ROS is being implicated in many diseases such as cancer, aging, and diabetes. The potential targets for the ROS in cells are membrane lipids, DNA and proteins. External supplementation through antioxidants is recommended to protect cells from the deleterious effects of such oxidative stress conditions. Earlier studies reported the presence of secondary metabolites (combretastatins) in the bark of the tree $C$. caffrum [9] and which is active against colon, lung and leukemia cancers. Some species of the family Combretaceae are used in African traditional medicines for the treatment of a variety of diseases, including hepatitis and malaria. However, no reports are available so far on any of the Indian species of family Combretaceae used as anticancer drug. Cambretastins A-4 compound is an anticancer molecule, which has a potent target in cancer chemotherapy in cell division [10]. In

\footnotetext{
${ }^{*}$ Corresponding author

E-mail address: dasarundhati2013@gmail.com
} 
Ethiopia, Combretum paniculatum is used for the treatment of ringworm and wounds [11]. The combretastatin is a family of stableness which act as anti-angiogenic agents, causing a vascular shutdown in tumor and resulting in tumour necrosis. A water-soluble analog, combretastatin A-4 phosphate (CA4), has shown promise in early clinical trials. This chemical has served as a model for the synthesis of a host of analogs containing the essential trimethoxy aryl moiety (Flavopiridol, Roscovitine) linked to substituted aromatic moieties through a variety of two or three atom bridges including heterocyclic rings and sulfonamides. This is an impressive display of the power of a relatively simple natural product structure to spawn a prolific output of medicinal and combinatorial chemistry. Keeping this in view, we have focused on the present investigation to identify the biologically active principle from the plants under family Combretaceae.

\section{Material and methods}

\subsection{Collection of plant materials}

The leaves and bark samples of Terminalia arjuna, T. alata, T. bellerica, T. catappa, T. chebulla, T. bucera, T. mauritiana, Combretum albidum, $C$. roxburghii, and $C$. indicum were collected from the different locations of Odisha. The herbarium of ten species under family combretaceae was presented in Fig.1. The leaves and barks were washed with deionized water, dried under shade for 48 hours. The dried leaves and barks were milled into a fine powder with the mechanical grinder and used for biochemical analysis.
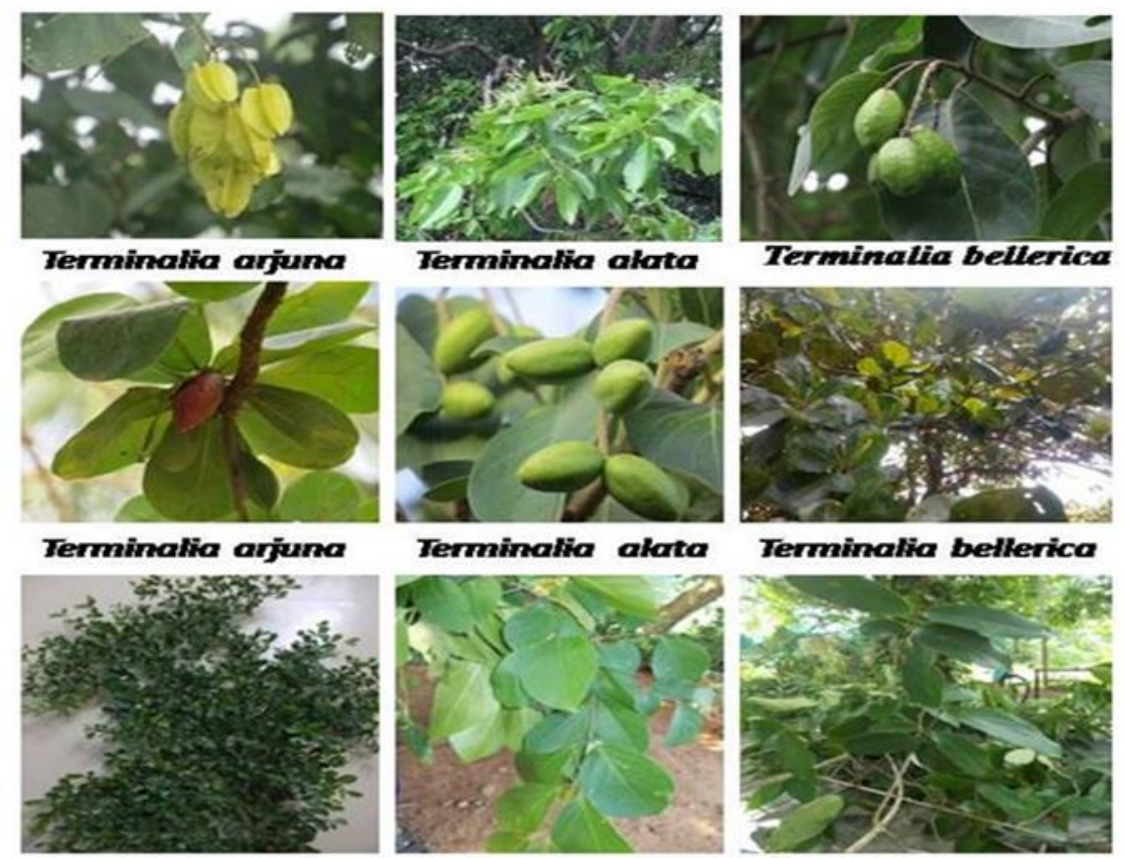

Terminalia catappa Combretum albidum Combretum roxburghi

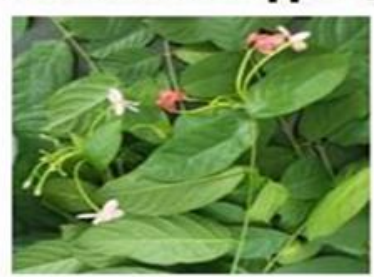

Combretum indicum

Figure 1 Ten different plant species of genus Terminalia and Combretum under family Combretaceae

\subsection{Extraction of plant samples}

For solvent extraction, $10 \mathrm{gm}$ of dried leaf and bark powder of each plant sample were taken separately and placed in the Soxhlet extraction apparatus. Acetone $(150 \mathrm{ml})$ was used as a solvent for extraction. Extraction was carried for 72 hours at the boiling point $\left(65^{\circ} \mathrm{C}\right)$ of the solvent. Then, the solvent was removed from crude extract at a reduced pressure with the help of a rotary vacuum evaporator to yield a viscous dark green residue and the extract was stored in $4{ }^{\circ} \mathrm{C}$ until further use. The fixed quantity of residue was dissolved in methanol and used for TLC \& HPTLC experiment. 


\subsection{Chromatography}

A standard of Combretastatin (A-4) (Sigma, USA) was used for the experiment. The standard solution of Combretastatin (A-4) $(1 \mathrm{mg} / \mathrm{ml})$ was prepared in methanol. The Silica gel $60 \mathrm{~F} 254$ aluminium plates (Merck, India) was used as a stationary phase. Ethyl acetate: methanol: water in the ratio of 40:5.4:4 was prepared and used as a mobile phase. All extracts were dissolved in methanol to have a final concentration of $1 \mathrm{mg} / \mathrm{ml}$ each. Chromatography was performed on aluminium plate pre-coated with silica gel $(60 \mathrm{~F} 25420 \times 10 \mathrm{~cm})[12,13] .$. Samples and standards were loaded on the plate as $6 \mathrm{~mm}$ wide bands with a CamagLinomat-V automatic TLC applicator positioned $15 \mathrm{~mm}$ from the lower edge of the plate and $20 \mathrm{~mm}$ from the side of the plate. The application parameters were identical for all the analyses performed. The plates were developed with the help of a mobile phase containing Ethyl acetate: methanol: water in the ratio $(40: 5.4: 4 \mathrm{v} / \mathrm{v} / \mathrm{v})$ under saturated condition $\left(25-30^{\circ} \mathrm{C}\right.$ and $40-50 \%$ relative humidity). After completion of the separation of compounds, the plate was air-dried and then vanillin spray solution $(0.1 \mathrm{~g}$ vanillin, $28 \mathrm{ml}$ methanol and 1 $\mathrm{ml}$ sulphuric acid) was uniformly sprayed over the chromatogram. Then the plate was heated at $105^{\circ} \mathrm{C}$ for the development of bands. Spots corresponding to the standard were scanned at $366 \mathrm{~nm}$ and $\mathrm{Rf}$ values were recorded with Camag Scanner-III in conjunction with win CATSV1.2.3 software. The quantity of Combretastatin (A4) present in each extract was calculated by comparing the peak area of the reference standard and respective samples.

\subsection{Qualitative analysis of antioxidant activity}

To detect antioxidant activity, a qualitative 2, 2 diphenyl-1-picrylhydrazyl (DPPH) assays was carried out. Qualitative screening of the constituents in each of the samples for antioxidant activity was done by TLC analysis. About $6 \mu$ of each sample was loaded on the TLC sheet and the chromatogram was developed in a solvent system, Ethyl acetate: methanol: water in the ratio (40:5.4:4 v/v/v). After that, the plates were first air-dried and then the chromatograms were sprayed with $0.2 \%$ 2, 2 diphenyl-1-picrylhydrazyl (DPPH) in methanol as an indicator [14]. The presence of antioxidant compounds was detected by yellow spots against a purple background on the TLC plates sprayed with $0.2 \%$ DPPH in methanol.

\subsection{Estimation of antioxidant enzymes}

Nature has endowed each cell with adequate protective mechanisms against any harmful effects of free radicals i.e. superoxide dismutase (SOD), Catalase (CAT), Guaiacol peroxidase (GP). The protein content of plants understudy was estimated by the Lowry method [15]. Antioxidants are substances that neutralize free radicals or their actions.

\subsection{Estimation of superoxide dismutase (SOD)}

Protein samples were taken out from liquid nitrogen for thawing and kept them on ice. Then, pre-warmed of all reagents except protein samples necessary for the SOD mixture. After that prepared blank test sample mixture without protein and buffer-A. Also prepared the first test samples, the mixture contains all components except H2O2. Reading was taken at $560 \mathrm{~nm}$. The calculation of SOD activity as $=$ SOD \% Inhibition $=$ Control OD - Treatment OD $/$ Control X 100 [16].

\subsection{Estimation of catalase (CAT)}

Protein samples were removed from liquid nitrogen for thawing and kept them on ice. Then pre-warmed all reagents except protein samples necessary for the catalase reaction then prepared a blank test sample without protein sample buffer A only. After that prepared mixture for the first test sample, the mixture contains all components except the protein sample. The sample was taken in a spectrophotometer cuvette and added the necessary amount of the protein sample and quickly mixed and measured absorbance against the blank test sample at $240 \mathrm{~nm}$ in 0 min and 3 min. Calculation of CAT activity ( $\mathrm{mM}$ of $\mathrm{H}_{2} \mathrm{O}_{2} / \mathrm{min} \mathrm{mg}$ of protein). Catalase activity = (A sample $3-\mathrm{A}$ sample 0$) /(\varepsilon$. d. t. c) $\varepsilon$ $=39.4 \mathrm{M}-1 \mathrm{~cm}-1\left(\mathrm{H}_{2} \mathrm{O}_{2}\right.$ extinction coefficient $)$ [17].

\subsection{Estimation of guaiacol peroxidase (GP)}

One gram of fresh leaf of each plant sample was taken in $3 \mathrm{ml}$ of $0.1 \mathrm{M}$ phosphate buffer for grinding in pre-chilled sterile mortar and pestle. After that ground leaf samples were centrifuged at $18,000 \mathrm{rpm}$ at $5^{\circ} \mathrm{C}$ for 15 minutes. Then the supernatant was collected as an enzyme source. After collection of supernatant in the eppendorf tube stored in the ice till the assay was carried out. Then $3 \mathrm{ml}$ of buffer solution, $0.5 \mathrm{ml}$ guaiacol solution, 0.1 ml enzyme extract and $0.03 \mathrm{ml}$ $\mathrm{H}_{2} \mathrm{O}_{2}$ was added in a cuvette and properly mixed for each sample separately. After that cuvette was placed in spectrophotometer and reading was taken at $436 \mathrm{~nm}$ and noted time required in minutes to increase the absorbance by 0.1 . Activity of Peroxidase $=\mu \mathrm{mols} / \mathrm{min} / \mathrm{mg}$.protein $=\Delta \mathrm{OD} / \Delta \mathrm{T} \mathrm{X} 1 / \mathrm{C} \mathrm{X} \mathrm{mg} \mathrm{protein} / 10$. 


\subsection{Antibacterial activity of plant crude extract}

Six bacterial strains viz. Streptococcus epidermis, Pseudomonas aeruginosa, Escherichia coli, Salmonella enterica, Staphylococcus aureus, and Bacillus subtillis were used in antibacterial potentiality test. These organisms were procured from the microbial type culture collection and gene bank, Institute of Microbial Technology, Chandigarh. From pure culture of each bacterial strain were transferred to Luria Britani liquid medium. Forty-eight hours of culture was taken for the test of the antibacterial assay using the disk diffusion technique. The discs ( $6 \mathrm{~mm}$ in diameter) were impregnated with $20 \mathrm{mg} / \mathrm{ml}, 40 \mathrm{mg} / \mathrm{ml}, 60 \mathrm{mg} / \mathrm{ml}, 80 \mathrm{mg} / \mathrm{ml}$ leaf and bark extracts of ten species and the discs were placed on seeded agar of each organism. The test plates were kept at $37^{\circ} \mathrm{C}$ in an incubator for 24 hours. The test plates were inspected visually to determine the growth of organisms and the diameter of zone of inhibition was measured in mm. The experiment was performed in triplicate and the average zone of inhibition.

\section{Results and discussion}

\subsection{Analysis of compound through TLC and HPTLC}

Combretastatin was identified from all of the leaf and bark extracts of tested plants through chromatograms after performing TLC (Figs. 2 \& 3). The HPTLC profile was developed by using the solvent system and individual peak scanned at a short wavelength of $366 \mathrm{~nm}$ to measure the retention value (Rf) and area unit (AU). The Rf value indicates the ratio of the distance moved by the solute (i.e. active constituents under test) and the distance moved by the solvent along with the stationary phase (i.e. HPTLC plate). The HPTLC images (after derivatization) have shown in Figs $4 \& 5$ indicate that the reference standard (combretastatin) and sample constituents were clearly separated on silica gel 60 F254 TLC plates. The constituent of the sample extracts was identified by comparison of bands in the sample with reference substances on the same plate. The identification of combretastatin in the leaf and bark extract was confirmed by UVvisible spectra of the extract with that of the standard within the same Rf value. The Rf values of the bands for a reference standard (combretastatin) were 7.0 and of the sample containing Combretastatins Rf value varies from 7.0-7.6. The phytochemical constituents of the twenty sample extracts were recognized by comparison of bands in the sample with reference to standard on the same HPTLC plate (Figs.3 \& 5). Combretastatin was found to be the major compound in all leaf and bark extracts of all the species of the family Combretaceae under study. The leaves of ten species of Combretaceae family exhibited a higher quantity of combretastatin than the bark samples of the same species under the family Combretaceae. The maximum content of combretastatin was recorded in the leaf extract of C.albidum (18565.6 AU). The maximum content of combretastatin content in the bark extract of Terminaliaarjuna (18266.4 AU).

\subsection{Enzymatic activity and antibacterial assay}

The presence of antioxidant enzyme activities was detected in the plant extracts using a qualitative 2, 2 diphenyl-1picrylhydrazyl (DPPH) assay which gives positive results in each of the experimental plants extract (Fig.6). Antioxidant activity of methanol and ethanol extract of all the parts T.arjuna and T. bellerica plants. The phenolic content was also high in methanolic extracts of T. bellerica leaves. DPPH free radical scavenging activity was studied by computation percentage inhibition of methanolic and ethanolic extracts in Terminalia species, the maximum percentage inhibition value was observed in methanolic extract of T.arjuna stem as well as bark [8]. SOD activity was reported good response in T. arjuna, T. bellerica, T. catappa, T. chebulla, T. bucera, Combretum albidum, C. roxburhii and C. indicum and less response in T. alata and T. mauritiana. Combretum albidum (61.013\% Inhibition of $\left.\mathrm{H}_{2} \mathrm{O}_{2}\right)$ was found with the best SOD activity (Fig.7). Catalase activity of ten plant species from family Combretaceae during the experiment was reported

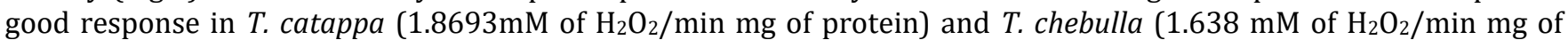
protein) more remarkable than rest of the plant under study (Fig.8). Guaiacol peroxidase activity of ten plant species from family Combretaceae showed variability. C. albidum was found to be the maximum activity (i.e. 0.1498 $\mu \mathrm{mols} / \mathrm{min} / \mathrm{mg}$ of protein) during the enzyme assay as compared to other plant species (Figure.9). Terminalia species have been reported to have good antioxidant, anticancer, antidiabetic, antiseptic, cardiotonic and anti-inflammatory effects have been established [18]. 


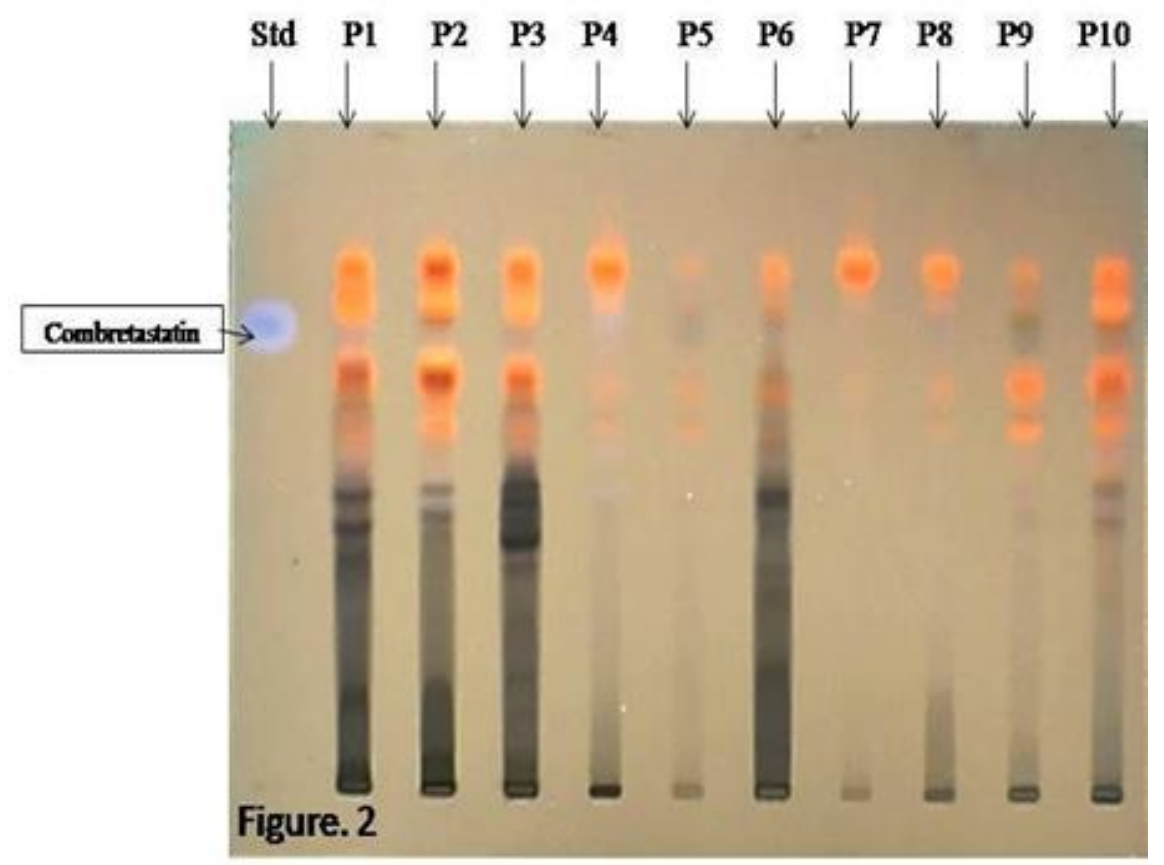

Figure 2 TLC profile of leaf extracts of 10 plant species under family Combretaceae . Standard $\neg-$ Combretastatin, P1T. arjuna, P2-T. alata, P3-T. bellerica ,T. T. cataappa, P5-T. chebulla, P6 - T. bucera, P7-Terminalia mauritiana, P8-C. albidum, P9-C. roxburghii and P10- C. indicum

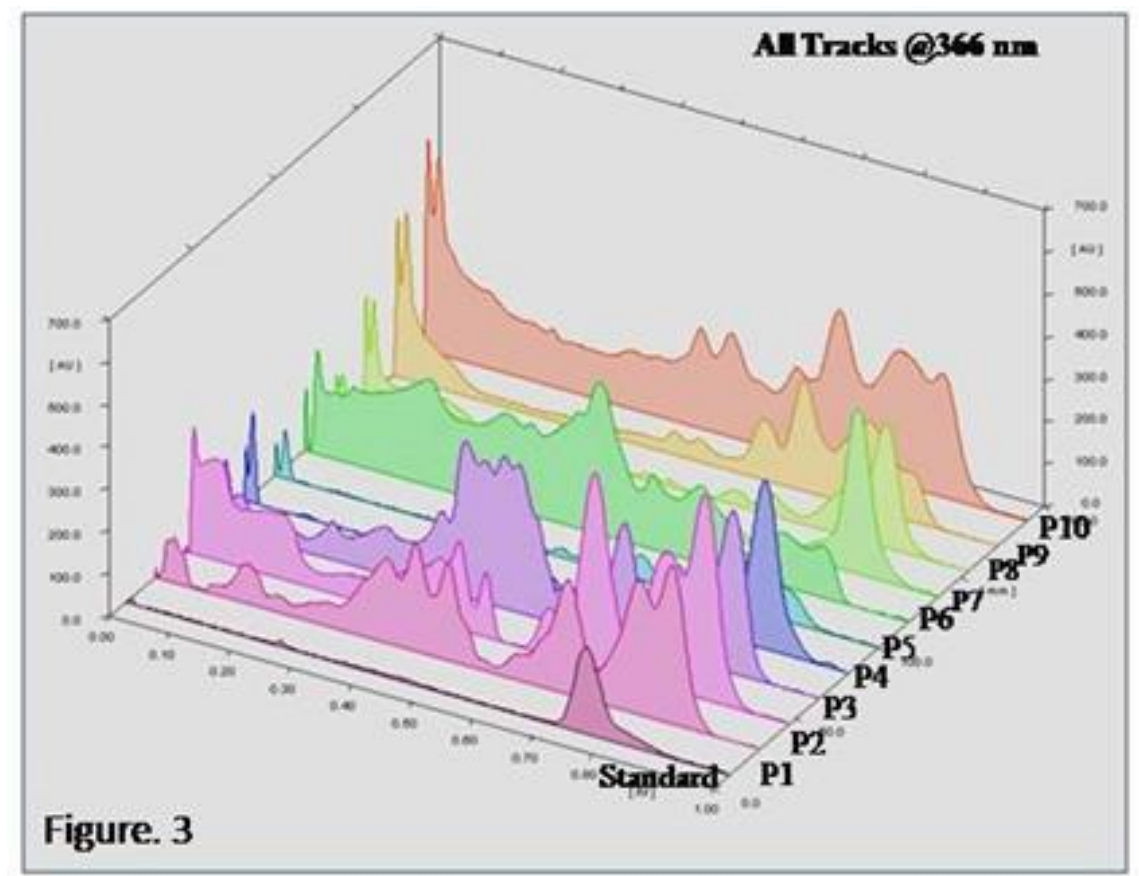

Figure 3 HPTLC profile of leaf extracts; of 10 plant species under family Combretaceae. Standard $า$ - Combretastatin, P1-T. arjuna, P2-T. alata, P3-T. bellerica ,T. cataappa, P5-T. chebulla, P6 - T. bucera, P7-Terminalia mauritiana, P8-C. albidum, P9-C. roxburghii and P10-C. indicum 


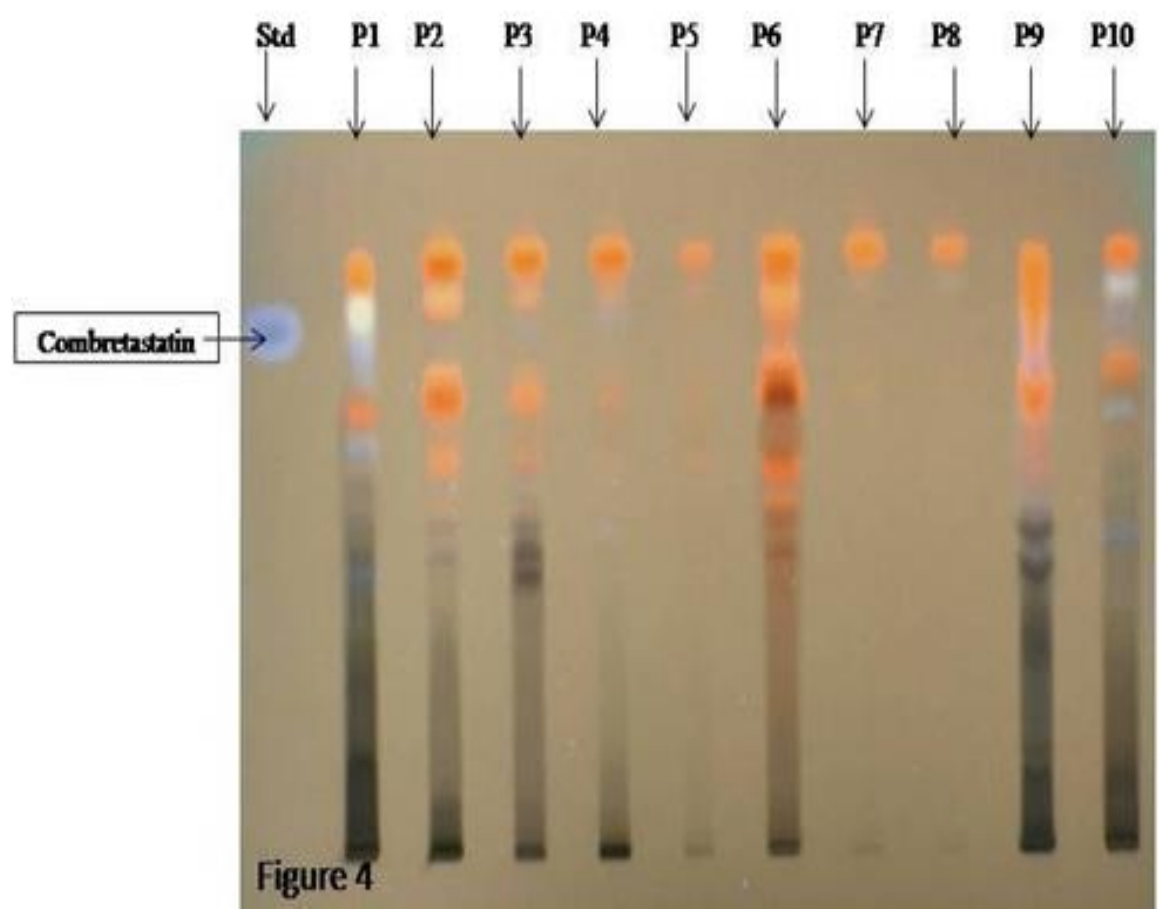

Figure 4 TLC profile of bark extracts of 10 plant species under family Combretaceae. Standard $า$ - Combretastatin, P1T. arjuna, P2-T. alata, P3-T. bellerica ,T. cataappa, P5-T. chebulla, P6 - T. bucera, P7-Terminalia mauritiana, P8-C. albidum, P9-C. roxburghii and P10- C. indicum

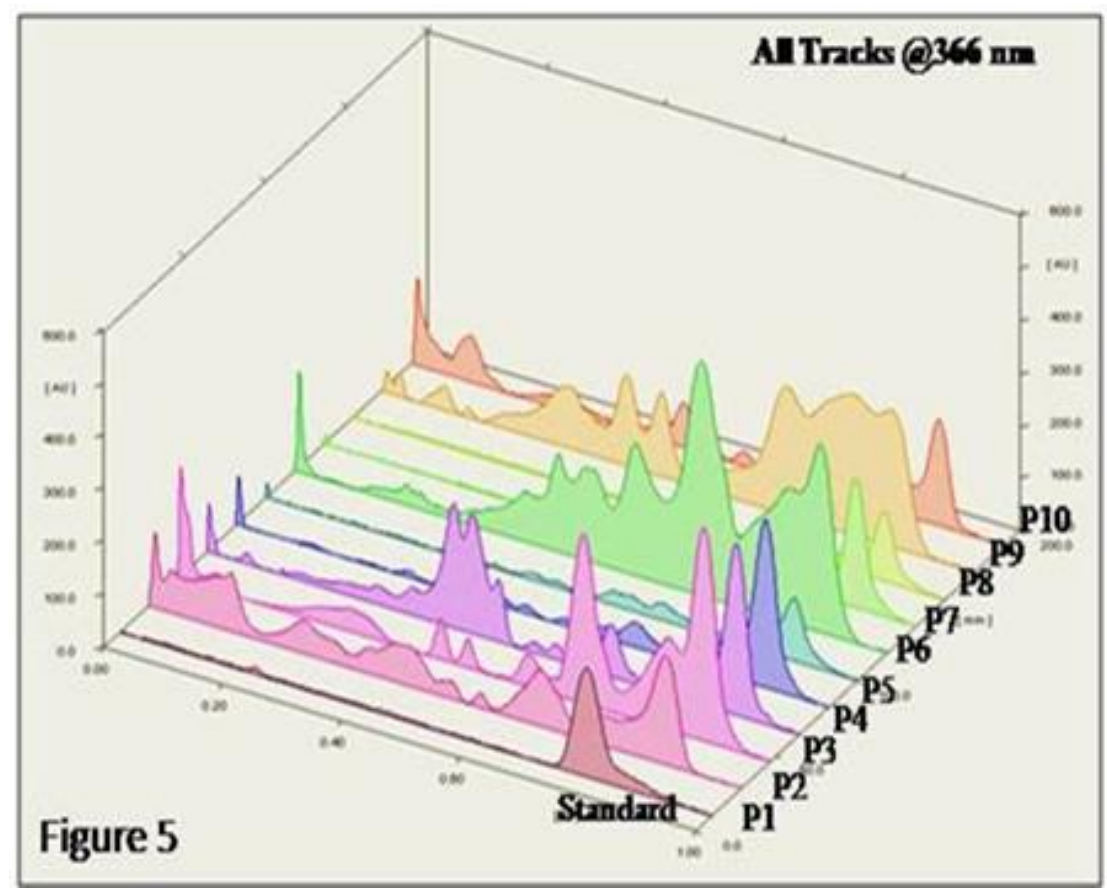

Figure 5 HPTLC profile of bark extracts of 10 plant species under family Combretaceae. Standard ᄀ- Combretastatin, P1-T. arjuna, P2-T. alata, P3-T. bellerica ,T. cataappa, P5-T. chebulla, P6 - T. bucera, P7-Terminalia mauritiana, P8-C. albidum, P9-C. roxburghii and P10-C. indicum 


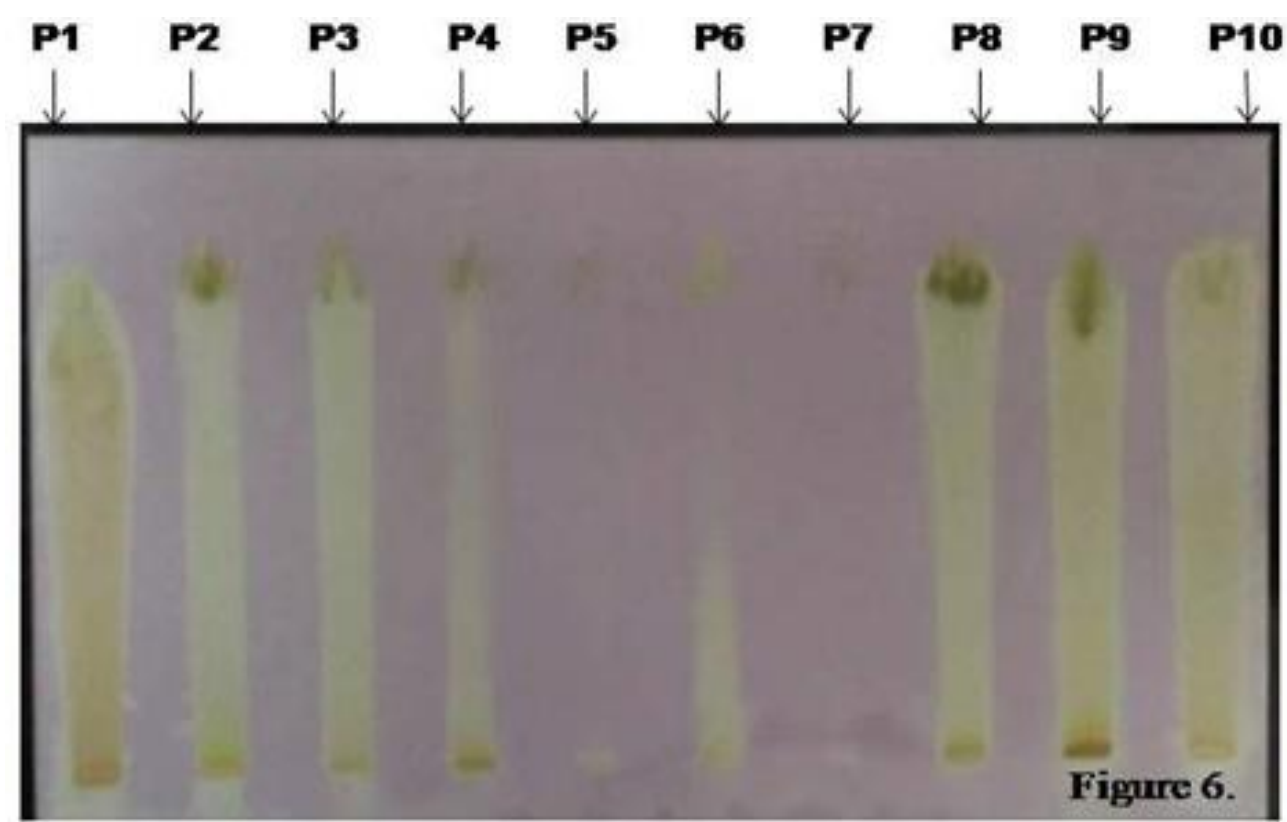

Figure 6 Qualitative analysis of antioxidant activity of leaf extracts of 10 species under family Combretaceae using DPPH method. P1-Terminalia arjuna, P2-T. alata, P3-T. T. cataappa, P5-T. chebulla, P6-T. bucera, P7-T. mauritiana, P8Combretumalbidum, P9-C. roxburghii, P10- C. indicum

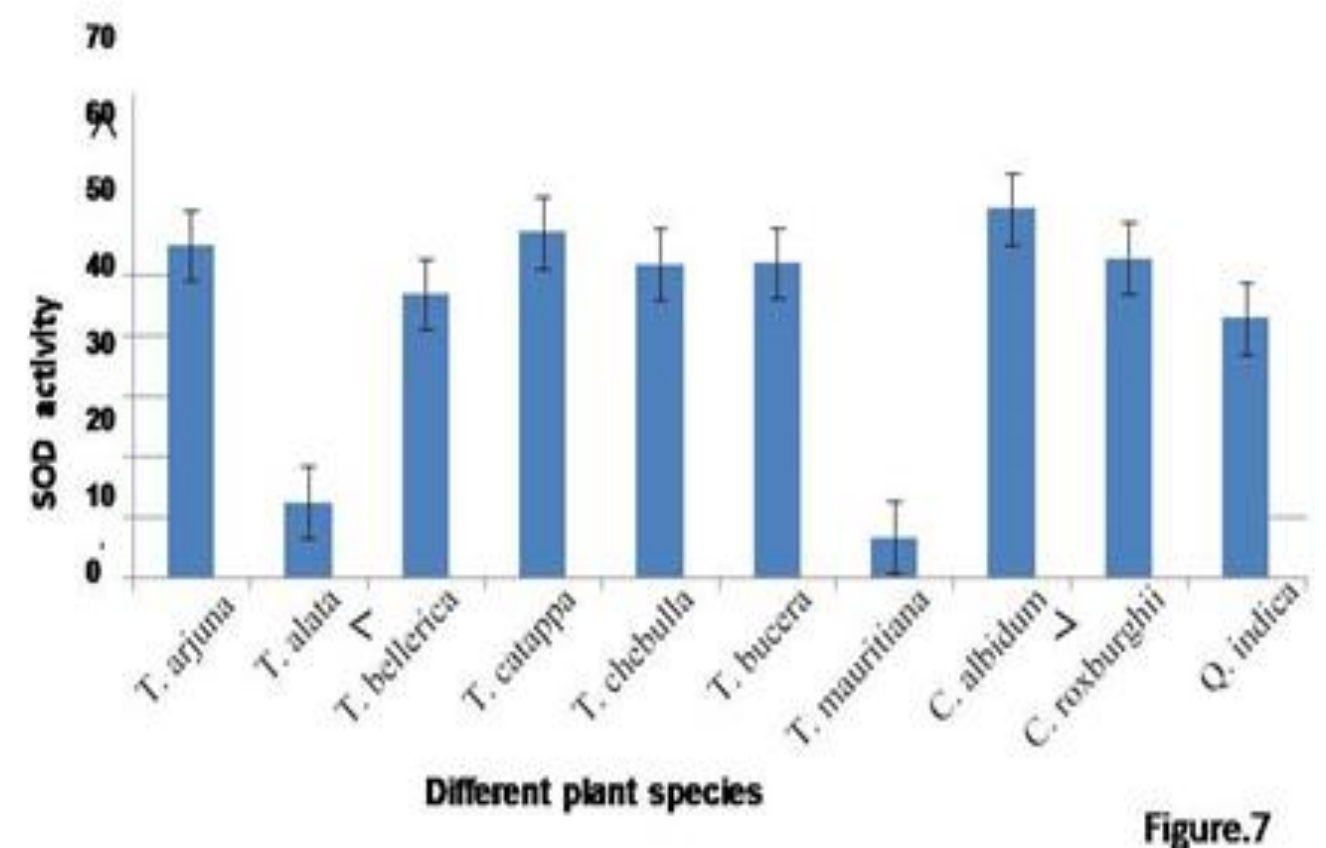

Figure 7 SOD activity of different plant species under family Combretaceae 


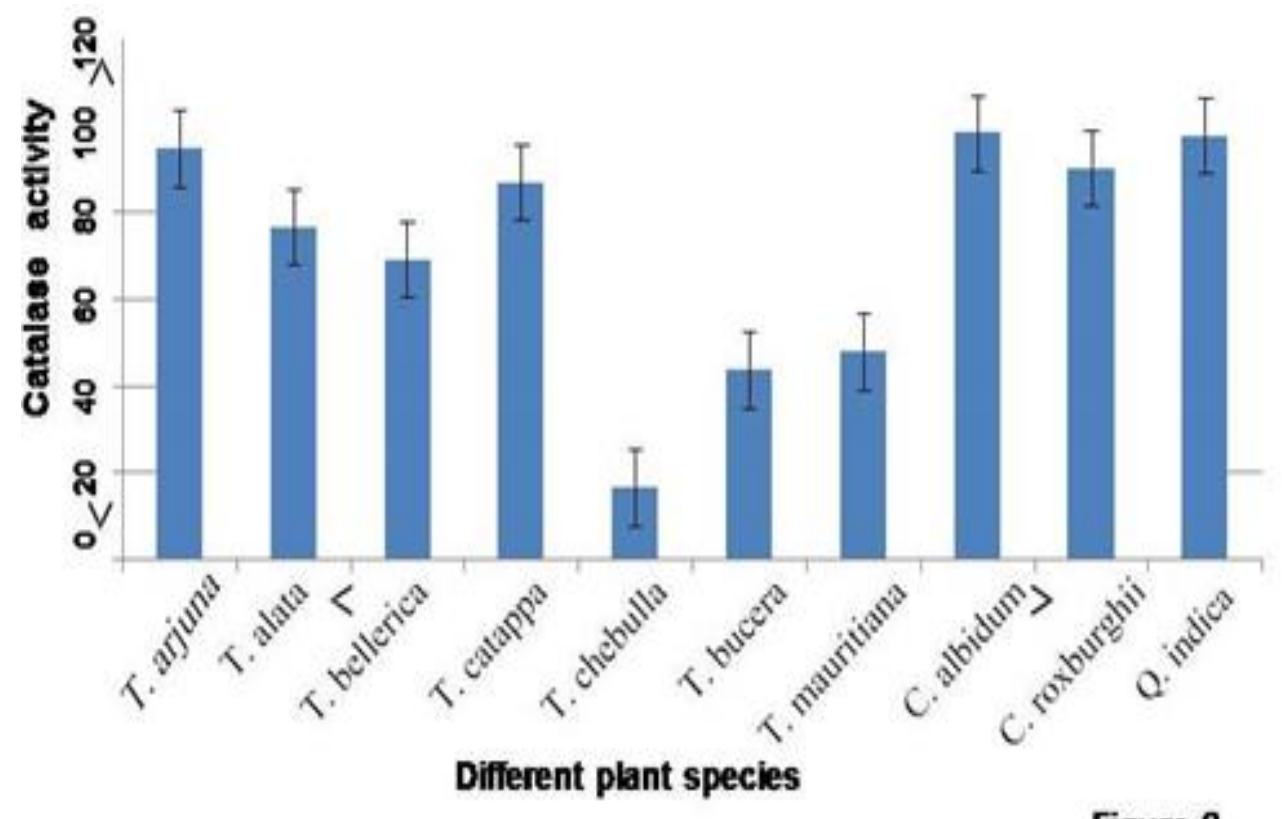

Figure.8

Figure 8 Catalase activity of 10 different plant species under family Combretaceae

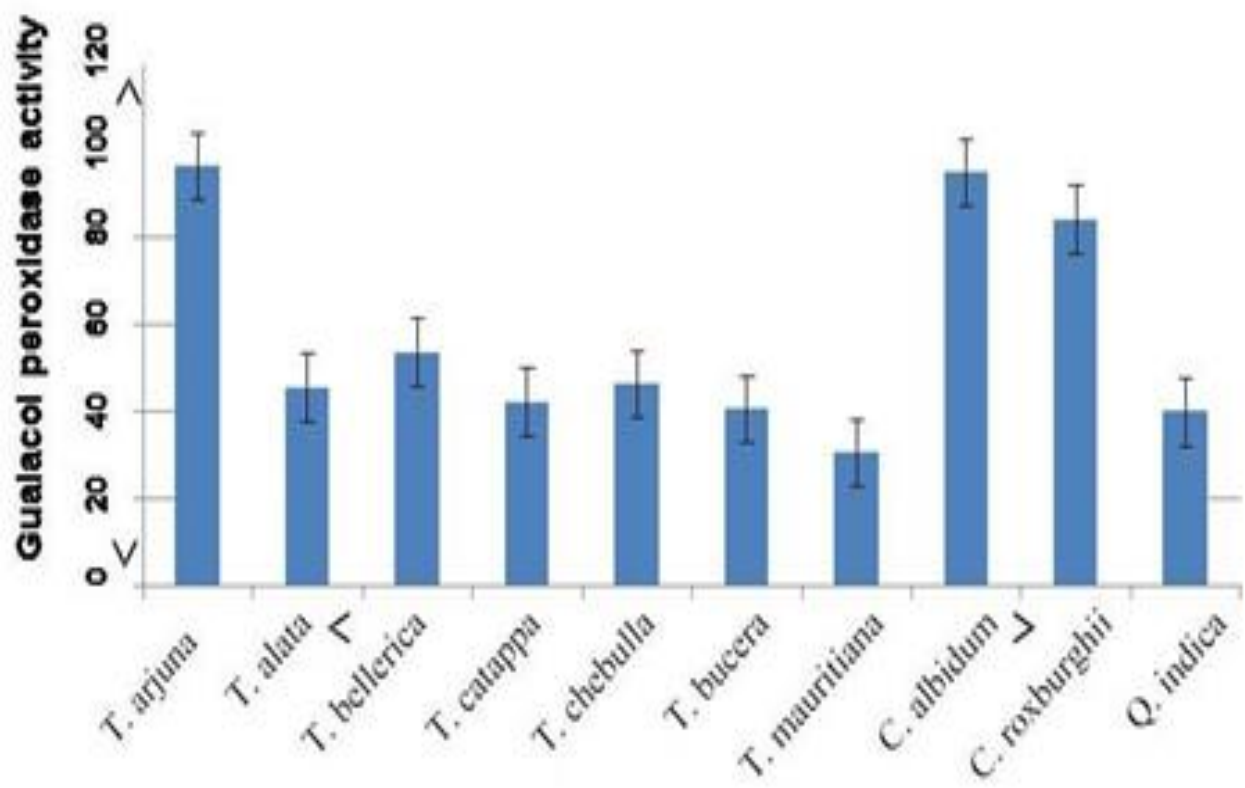

Different plant species

Figure 9

Figure 9 Guaiacol peroxidaseactivity of 10 different plant species under family Combretaceae

Antibacterial properties of ten different species such as Terminali aarjuna, Terminalia alata, T. bellerica, T.T. cataappa, T. chebulla, T. bucera and T. mauritiana, Combretum albidum, C. roxburghii, and C.indicum were tested under control condition. Four different concentrations $(20,40,60$ and $80 \mathrm{mg} / \mathrm{ml})$ of methanolic extracts of leave and bark of these ten plant species were tested against six bacterial pathogens i.e.Streptococcus epidermis, Salmonella enterica, Staphylococcus aureus, Escherichia coli, Bacillus subtillis and Pseudomonas aeruginosa using disc diffusion method. Methanolic extract of Terminalia arjuna leaf and bark given best result against Streptococcus epidermis with a remarkable zone of inhibition i.e. $17.6 \mathrm{~mm}$ and $15.3 \mathrm{~mm}$ in $80 \mathrm{mg} / \mathrm{ml}$ concentration respectively and also against of 
Escherichia coli . T.arjuna leaf and bark exhibited the best result with $21.2 \mathrm{~mm}$ and $16.4 \mathrm{~mm}$ zone of inhibition respectively. In the case of Pseudomonas aeruginosa, leaf and bark of T.arjuna showing remarkable good results with $17.5 \mathrm{~mm}$ and $14.8 \mathrm{~mm}$ respectively. Leaf and bark extract of $T$. chebulla showed the best result against Salmonella enterica showing $19.2 \mathrm{~mm}$ and $16.7 \mathrm{~mm}$ of the zone of inhibition respectively. T. chebulla leaf and bark extract showing the best result against Staphylococcus aureus having $22.6 \mathrm{~mm}$ and $20.1 \mathrm{~mm}$ of the zone of inhibition respectively. Leaf and bark extract of Combretum albidum showed the best result against Bacillus subtillis showing $22.4 \mathrm{~mm}$ and $18.6 \mathrm{~mm}$ respectively. Phenolic compounds from the fruit of T.chebula exhibited good antioxidant properties and remarkable recovery of balancing the nervous system as reported earlier [7,19]. Terminaliaand Combretumspecies have various medicinal properties including antibacterial, anti-inflammatory and therapeutic potential as reported by various researchers $[6,19,20]$.

\section{Conclusion}

In conclusion, the chemo-profiling study of the chemical constituents of the leaves and bark extract of ten different plant species under family Combretaceae namely T.arjuna, T. alata, T. bellerica, T.T. cataappa, T. chebulla, T. bucera and T. mauritiana, Combretum albidum, C. roxburghii and C.indicum showed the presence of an anticancer compound (Combretastatin A-4). For the detection of the presence of antioxidant activity in the plant extract, qualitative 2, 2 diphenyl-1-picrylhydrazyl (DPPH) assay showed a positive results. On the basis of the antibacterial study, it is observed that the pronounceable activity of T.arjuna, T. chebulla and Combretum albidum leaf and bark extract against the different bacterial strains.

\section{Compliance with ethical standards}

\section{Acknowledgments}

We are thankful to the Prof. and Head, Department of Agril. Biotechnology, College of Agriculture, Bhubaneswar for providing facility to carry out research work. The facility created under the FIST grant and DBT-HRD program are greatly acknowledge. The author (AD) wish to acknowledge to UGC, New Delhi for providing fellowship for the research.

\section{Disclosure of conflict of interest}

The authors declare that they have no conflicts of interest.

\section{References}

[1] Martini ND, Katerere DRP and Eloff JN. (2004). Biological activity of five antibacterial flavonoids from Combretum erythrophyllum (Combretaceae). Jour. of Ethnopharmacology, 93,207-212.

[2] Richardson MA. (2001). Bio pharmacologic and herbal therapies for cancer: research update from National Centre for complementary and alternative medicine, Journal of Nutrition, 131(11), 3037S-3040S.

[3] Farnsworth NR and Soejarto DD. (1991).Global importance of medicinal plants. In: Akerele O., Heywood V. and Synge H. (eds) The conservation of medicinal plants. Cambridge University Press, Cambridge, UK, 25-51.

[4] Verpoorte R. (2000). Pharmacognosy in the New Millenium: Lead finding and biotechnology, Journal of Pharmacy and Pharmacology, 52, 253-262.

[5] SowemimoAA, Van de Venter M, Baatjies L and Koekemoer T. (2009). Cytotoxic activity of selected Nigerian plants. African Journal of Traditional and Alternative Medicines. 6(4), 526-528.

[6] Bhatnagar B, Sahoo S, Mohapatra AK and Behera DR. (2012). Phytochemical analysis, Antioxidant and Cytotoxic activity of medicinal plant Combretum roxburghii (Family: Combretaceae), Int. Journal. Drug Dev. \& Res., 4(1), 193-202.

[7] Chandel SR, Kumar V, Guleria S, Sharma N, Sourirajan A, Khosla PK, Baumler DJ and Dev K. (2019). Sequential Fractionation by Organic Solvents Enhances the Antioxidant and Antibacterial Activity of Ethanolic Extracts of Fruits and Leaves of Terminalia bellerica from North Western Himalayas, India. Pharmacog. Journal, 11(1), 94101.

[8] Beigi M, Haghani E, Alizadeh A and Samani ZN. (2018). The pharmacological properties of several species of Terminalia in the world. International Journal of Pharmaceutical Sciences and Research, 9(10), 4079-4088. 
[9] Pettit GR, Singh SB, Hamel E, Lin CM,Alberts DS and Garcia-Kendall D. (1989). Isolation and structure of the strong cell growth and tubulin inhibitor combretastatin A-4. Experientia, 45(2), 209-211.

[10] Pettit GR, Singh SB, Schmidt JM, Niven ML, Hamel E and Lin CM. (1988). Isolation, structure, synthesis, and antimitotic properties of combretastatins B-3 and B-4 from Combretum caffrum. Journal of Natural Products, 51(3), 517- 527.

[11] Abera B. (2014). Medicinal plants used in traditional medicine by Oromo people, Ghimbi District, Southwest Ethiopia. Journal of Ethnobiology and Ethnomedicine, 10, 40.

[12] Stahl E. (1969). Thin Layer Chromatography. 2nd Edn Springer-Verlag,New York.

[13] Das A, Samal KC, Das AB and Rout GR. (2018). Quantification, Antibacterial Assay and Cytotoxic Effect of Combretastatin, an Anticancer Compound from Three Indian Combretum species. Int. J. Curr.Microbiol.App.Sci., 7, 687-699.

[14] Deby C and Magotteaux G. (1970). Relationship between essential fatty acids and tissue antioxidant levels in mice. SocBiolFil., 164(12),2675-2681.

[15] Lowry OH, Rosenbrough NJ, Farr AL and Randall RJ. (1951). Protein measurement with theFolin Phenol Reagent. Journal of Biological Chemistry, 193,265-275.

[16] Beauchamp C and Fridovich I. (1971). Superoxide dismutase: improved assays and an assay applicable to acrylamide gels. Analytical Biochemistry, 44, 276-287.

[17] Abei H. (1984). Catalase in vitro. Methods in Enzymology. Science Direct, Elsevier, 105, 121 - 126.

[18] Cock IE. (2015).The medicinal properties and phytochemistry of plants of the genus Terminalia (Combretaceae). Inflammopharmacology, 23(5), 203-229.

[19] Kolla JN, Kulkarni N, Kura RR and Theepireddy SKR. (2017). Terminalia chebula Retz.-an important medicinal plant. HerbaPolorica, 63(4), 45-56.

[20] Das N, Goshwami D, Md. Hasan S, Mahmud ZAL and Raihan SZ. (2016). Evaluation of antioxidant, antimicrobial and cytotoxic activities of Terminalia citrine leaves. Journal of Pharmacy Research, 10(1), 8-15.

\section{How to cite this article}

Das A, Samal KC and Bastia AK. (2020). Chemo-profiling and assessment of antioxidant activity and antibacterial potentials of selected plants of family Combretaceae. GSC Biological and Pharmaceutical Sciences, 10(2), 30-39. 